\title{
GENERALIZED PRACTICAL STABILITY RESULTS BY PERTURBING LYAPUNOV FUNCTIONS
}

\author{
DONNA STUTSON and A.S. VATSALA \\ University of Southwestern Louisiana \\ Department of Mathematics \\ Lafayette, LA 70504-1010 USA
}

(Received March, 1995; Revised August, 1995)

\begin{abstract}
It is known that practical stability is neither stronger nor weaker than Lyapunov stability. In this paper we combine perturbing Lyapunov technique with stability in terms of two measures to obtain nonuniform practical stability results under weaker assumptions. We also use comparison methods to obtain these results.
\end{abstract}

Key words: Practical Stability, Perturbing Lyapunov Functions.

AMS (MOS) subject classifications: 34D10, 34D20.

\section{Introduction}

It is well-known [6] that stability and even asymptotic stability themselves are neither necessary nor sufficient to ensure practical stability. The desired state of a system may be mathematically unstable; however, the system may oscillate sufficiently close to the desired state, and its performance is deemed acceptable. It is also known [6] that practical stability is neither weaker nor stronger than the usual stability; an equilibrium can be stable in the usual sense, but not practically stable, and vice versa. Practical stability is, in a sense, a uniform boundedness of the solution relative to the initial conditions, but the bound must be sufficiently small.

Lyapunov's second method, also known as the direct method, is a widely recognized and used technique for studying the stability of nonlinear systems. This method employs the construction of a Lyapunov function. Unfortunately, a Lyapunov function may not satisfy all the desired conditions. As a result, one may find it more advantageous to perturb that Lyapunov function as opposed to discarding it [5]. Also, through the use of two measures [5], rather than the usual norm, one can unify a variety of earlier known boundedness and stability results.

In this paper, we obtain practical results via perturbing Lyapunov function techniques and in terms of two measures. We also use the comparison method to obtain our results. These result refine the earlier results in [5], and are analogous to the composite boundedness results in [7]. 


\section{Preliminaries}

Let us list the following definitions and classes of functions:

$K=\left[\sigma \in C\left[[\rho, \infty), \mathbb{R}_{+}\right]: \quad \sigma(u)\right.$ is strictly increasing and $\sigma(u) \rightarrow \infty$ as $\left.u \rightarrow \infty\right]$,

$C K=\left[\sigma \in C\left[\mathbb{R}_{+} \times[\rho, \infty), \mathbb{R}_{+}\right]: \quad \sigma(t, u) \in K\right.$ for each $\left.t \in \mathbb{R}_{+}\right]$,

$\Gamma=\left[h \in C\left[\mathbb{R}_{+} \times \mathbb{R}^{n}, \mathbb{R}_{+}\right]: \inf _{x \in R^{n}} h(t, x)=0\right.$ for each $\left.t \in \mathbb{R}_{+}\right]$.

Consider the differential system

$$
\begin{gathered}
x^{\prime}=f(t, x) \\
x\left(t_{0}\right)=x_{0}, \quad t_{0} \geq 0
\end{gathered}
$$

where $f \in C\left[\mathbb{R}_{+} \times \mathbb{R}^{n}, \mathbb{R}^{n}\right]$. We shall assume, for convenience, that $f$ is smooth enough to ensure global existence of solutions of (2.1).

Definitions: Let $h_{0}, h \in \Gamma$. Then differential system (2.1) is said to be

$\left(P S_{1}\right) \quad\left(h_{0}, h\right)$-practically stable if given $(\lambda, A)$ with $0<\lambda<A$, we have $h_{0}\left(t_{0}, x_{0}\right) \leq \lambda$ implies $h(t, x(t))<A$, for some $t_{0} \in \mathbb{R}_{+}$, where $x(t)=x\left(t, t_{0}, x_{0}\right)$ is any solution of $(2.1)$;

$\left(P S_{2}\right) \quad\left(h_{0}, h\right)$-uniformly practically stable if $\left(P S_{1}\right)$ holds for all $t_{0} \in \mathbb{R}_{+}$;

$\left(P S_{3}\right) \quad\left(h_{0}, h\right)$-practically quasi-stable if given $(\lambda, T, B)>0$ and some $t_{0} \in \mathbb{R}_{+}$, we have $h_{0}\left(t_{0}, x_{0}\right) \leq \lambda$ implies $h(t, x(t))<B, t \geq t_{0}+T$

$\left(P S_{4}\right) \quad\left(h_{0}, h\right)$-uniform practically-quasi stable if $\left(P S_{3}\right)$ holds for all $t_{0} \in \mathbb{R}_{+}$;

$\left(P S_{5}\right) \quad\left(h_{0}, h\right)$-strongly practically stable if $\left(P S_{1}\right)$ and $\left(P S_{3}\right)$ hold together;

$\left(P S_{6}\right) \quad\left(h_{0}, h\right)$-strongly uniformly practically stable if $\left(P S_{2}\right)$ and $\left(P S_{4}\right)$ hold together;

$\left(S_{1}\right) \quad\left(h_{0}, h\right)$-equi-attractive in the large if for each $\epsilon>0, \alpha>0$ and $t_{0} \in \mathbb{R}_{+}$, there exists a positive number $T=T\left(t_{0}, \epsilon, \alpha\right)$ such that $h_{0}\left(t_{0}, x_{0}\right)<\alpha$ implies $h(t, x(t))<\epsilon$, $t \geq t_{0}+T$

$\left(S_{2}\right) \quad\left(h_{0}, h\right)$-uniformly attractive in the large if $\left(S_{1}\right)$ holds for $T=T(\epsilon, \alpha)$;

$\left(P S_{7}\right) \quad\left(h_{0}, h\right)$-asymptotically practically stable if $\left(P S_{1}\right)$ and $\left(S_{1}\right)$ hold together with $\alpha=\lambda$.

See $[3,5]$ for more definitions.

We will need the following theorem to develop our main results [5].

Theorem 2.1: Let $V(t, x) \in C\left[\mathbb{R}_{+} \times \mathbb{R}^{n}, \mathbb{R}_{+}\right]$and $V(t, x)$ is locally Lipschitzian in $x$ for each $t \in \mathbb{R}_{+}$. Assume further that the function $D^{+} V(t, x)$ satisfies

$$
D^{+} V(t, x) \leq g(t, V(t, x)), \quad(t, x) \in \mathbb{R}_{+} \times \mathbb{R}^{n},
$$

where $g \in C\left[\mathbb{R}_{+} \times \mathbb{R}, \mathbb{R}\right]$. Let $r(t)=r\left(t, t_{0}, u_{0}\right)$ be the maximal solution of

$$
u^{\prime}=g(t, u), \quad u\left(t_{0}\right)=u_{0}
$$

existing on $J=\left[t_{0}, t_{0}+\alpha\right), 0 \leq \alpha \leq \infty$. Then for any solution $x(t)=x\left(t, t_{0}, x_{0}\right)$ of $(2.1)$ existing on $J, V\left(t_{0}, x_{0}\right) \leq u_{0}$ implies that $V(t, x(t)) \leq r(t), t \in J$.

\section{Main Results}

Theorem 3.1: Assume that

$\left(A_{1}\right) \quad(\lambda, A)>0$ with $0<\lambda<A$; 
$\left(A_{2}\right) \quad h_{0}, h_{1}, h_{2} \in \Gamma, h_{1}(t, x(t)) \leq \varphi_{1}(t, x(t)), h_{2}(t, x(t)) \leq \varphi_{2}\left(t, h_{0}(t, x(t))\right)$, whenever $h_{0}(t, x(t))<\lambda$ and $\varphi_{1}(t, x(t)), \varphi_{2}(t, x(t)) \in C K$;

$\left(A_{3}\right) \quad V_{0}(t, x) \in C\left[\mathbb{R}_{+} \times \mathbb{R}^{n}, \mathbb{R}_{+}\right], V_{0}(t, x)$ is locally Lipschitzian in $x$ and

(a) $V_{0}(t, x) \leq a_{0}\left(t, h_{0}(t, x)\right)$ for $(t, x) \in S\left(h_{0}, \lambda\right)$, where $a_{0}(t, x) \in C K$;

(b) $\quad D^{+} V_{0}(t, x) \leq g_{0}\left(t, V_{0}\right)$ on $\mathbb{R}_{+} \times \mathbb{R}^{n}$, where $g_{0}(t, u) \in C[\mathbb{R}+\times \mathbb{R}+, \mathbb{R}]$;

$\left(A_{4}\right) \quad V_{1}(t, x) \in C\left[\mathbb{R}_{+} \times S^{c}\left(h_{1}, \lambda\right) \cap S\left(h_{1}, A\right), \mathbb{R}_{+}\right], V_{1}(t, x)$ is locally Lipschitzian in $x$ and

(a) $b_{1}\left(h_{1}(t, x)\right) \leq V_{1}(t, x)$;

(b) $\quad V_{1}(t, x) \leq a_{1}\left(h_{1}(t, x)\right)+V_{0}(t, x)$;

(c) $D^{+}\left(V_{1}(t, x)+V_{0}(t, x)\right) \leq g_{1}\left(t, V_{1}(t, x)+V_{0}(t, x)\right)$ on $S^{c}\left(h_{1}, A\right) \cap S^{c}\left(h_{1}, \lambda\right)$ where $a_{1}, b_{1} \in K$ and $g_{1}(t, w) \in C\left[\mathbb{R}_{+} \times \mathbb{R}+, \mathbb{R}\right]$;

$\left(A_{5}\right) \quad$ For each $A>L(\lambda)>0, V_{2}(t, x) \in C\left[\mathbb{R}_{+} \times S\left(h_{2}, A\right) \cap S^{c}\left(h_{2}, L(\lambda)\right) \cap S\left(h_{1}, L(\lambda)\right), \mathbb{R}_{+}\right]$; $V_{2}(t, x)$ is locally Lipschitzian in $x$ and

(a) $\quad V_{2}(t, x) \leq a_{2}\left(h_{1}(t, x)+h_{2}(t, x)\right)+V_{0}(t, x)$ on $S\left(h_{2}, A\right) \cap S^{c}\left(h_{2}, L(\lambda)\right) \cap S\left(h_{1}, L(\lambda)\right)$;

(b) $\quad b_{2}\left(h_{2}(t, x)\right) \leq V_{2}(t, x)$ on $S\left(h_{2}, A\right) \cap S^{c}\left(h_{2}, L(\lambda)\right) \cap S\left(h_{1}, L(\lambda)\right)$;

(c) $\quad D^{+}\left(V_{2}(t, x)+V_{0}(t, x)\right) \leq g_{2}\left(t, V_{2}(t, x)+V_{0}(t, x)\right) \quad$ on $\quad S\left(h_{2}, A\right) \cap S^{c}\left(h_{2}, L(\lambda)\right) \cap$ $S\left(h_{1}, L(\lambda)\right)$, where $a_{2}, b_{2} \in K$ and $g_{2}(t, v) \in C[\mathbb{R}+\times \mathbb{R}+, \mathbb{R}]$;

$\left(A_{6}\right) \quad a_{1}(A)+a_{0}\left(t_{0}, \lambda\right)<b_{1}(A), \quad a_{2}(2 A)+3 a_{0}\left(t_{0}, \lambda\right)<b_{2}(A), \quad \varphi_{1}\left(t_{0}, \lambda\right)<A$ and $\varphi_{2}\left(t_{0}, \lambda\right)<A$ hold for some $t_{0} \in \mathbb{R}_{+}$;

$$
\begin{array}{cc}
u^{\prime}=g_{0}(t, u), \quad u\left(t_{0}\right)=u_{0} \\
w^{\prime}=g_{1}(t, w), \quad w\left(t_{0}\right)=w_{0} \\
v^{\prime}=g_{2}(t, v), \quad v\left(t_{0}\right)=v_{0} .
\end{array}
$$

If (2.2) is practically stable, (2.3) and (2.4) are uniformly practically stable, then the system (2.1) is $\left(h_{0}, h_{1}\right)$-practically stable and $\left(h_{0}, h_{2}\right)$-practically stable.

Proof: Since $(2.2)$ is practically stable with respect to $\left(a_{0}\left(t_{0}, \lambda\right), \frac{3}{2} a_{0}\left(t_{0}, \lambda\right)\right)>0$, then $u_{0}<a_{0}\left(t_{0}, \lambda\right)$ implies

$$
u(t)<\frac{3}{2} a_{0}\left(t_{0}, \lambda\right), \quad t \geq t_{0} \text { for some } t_{0} \in R_{+} .
$$

Suppose $h_{0}\left(t_{0}, x_{0}\right)<\lambda$ for some solution $x(t)=x\left(t, t_{0}, x_{0}\right)$ of $(2.1)$. Then from assumptions $\left(A_{2}\right)$ and $\left(A_{6}\right)$, we have that $h_{1}\left(t_{0}, x_{0}\right) \leq \varphi_{1}\left(t_{0}, \lambda\right) \equiv \alpha_{1}<A$. Let $\eta=\max \left\{\lambda, \alpha_{1}\right\}$. If (2.1) is not $\left(h_{0}, h_{1}\right)$-practically stable, there exists $t_{1}$ and $t_{2}$ such that $t_{2}>t_{1}>t_{0}$,

$$
\begin{gathered}
h_{1}\left(t_{1}, x\left(t_{1}\right)\right)=\eta, h_{1}\left(t_{2}, x\left(t_{2}\right)\right)=A \text { and } \\
\eta \leq h_{1}(t, x) \leq A \text { for } t \in\left[t_{1}, t_{2}\right], \text { whenever } h_{0}\left(t_{0}, x_{0}\right) \leq \lambda .
\end{gathered}
$$

By assumption $\left(A_{3}\right)(a), V_{0}\left(t_{0}, x_{0}\right) \leq a_{0}\left(t_{0}, \lambda\right)$, and by $\left(A_{2}\right)(b), D^{+} V_{0}(t, x) \leq g_{0}\left(t, V_{0}(t, x)\right)$ on $\left[t_{0}, t_{1}\right]$. Therefore, by Theorem 2.1 ,

$$
V_{0}(t, x) \leq r_{0}\left(t, t_{0}, V_{0}\left(t_{0}, x_{0}\right)\right)
$$

where $\left.r_{0}\left(t, t_{0}, V_{0}, t_{0}, x_{0}\right)\right)$ is the maximal solution of (2.2). Consequently,

$$
V_{0}(t, x(t)) \leq \frac{3}{2} a_{0}\left(t_{0}, \lambda\right) \text { on }\left[t_{0}, t_{1}\right]
$$

by (2.5). Also, $(2.3)$ is uniformly practically stable with respect to $\left(a_{1}(A)+3 a_{0}\left(t_{0}, \lambda\right), b_{1}(A)\right)>$ 0 . Therefore, 


$$
w_{0}<a_{1}(A)+3 a_{0}\left(t_{0}, \lambda\right) \text { implies that } w(t)<b_{1}(A), t \geq t_{0}
$$

for any $t_{0} \in \mathbb{R}_{+}$. By assumption $\left(A_{4}\right)(b)$ and $(2.6)$,

$$
\begin{aligned}
V_{1}\left(t_{1}, x\left(t_{1}\right)\right)+V_{0}\left(t_{1},\right. & \left.x\left(t_{1}\right)\right) \leq a_{1}\left(h_{1}\left(t_{1}, x\left(t_{1}\right)\right)\right)+2 V_{0}\left(t_{1}, x\left(t_{1}\right)\right) \\
\leq & a_{1}(\eta)+2\left(\frac{3}{2} a_{2}\left(t_{0}, \lambda\right)\right) \\
& \leq a_{1}(\eta)+3 a_{0}\left(t_{0}, \lambda\right) \\
& \leq a_{1}(A)+3 a_{0}\left(t_{0}, \lambda\right)
\end{aligned}
$$

and

$$
D^{+}\left(V_{1}(t, x(t))+V_{0}(t, x(t))\right) \leq g_{1}\left(t, V_{1}(t, x(t))+V_{0}(t, x(t))\right) \text { on }\left[t_{1}, t_{2}\right]
$$

Therefore, by Theorem 2.1,

$$
V_{1}(t, x(t))+V_{0}(t, x(t)) \leq r_{1}\left(t, t_{1}, V_{1}\left(t_{1}, x\left(t_{1}\right)\right)+V_{0}\left(t_{1}, x\left(t_{1}\right)\right)\right)
$$

where $r_{1}\left(t, t_{1}, V_{1}\left(t_{1}, x\left(t_{1}\right)\right)+V_{0}\left(t_{1}, x\left(t_{1}\right)\right)\right)$ is the maximal solution of (2.3). Consequently, by $\left(A_{4}\right)(a)$ and $(2.8)$, we obtain

$$
b_{1}(A) \leq V_{1}\left(t_{2}, x\left(t_{2}\right)\right)+V_{0}\left(t_{2}, x\left(t_{2}\right)\right)<b_{1}(A)
$$

which is a contradiction. Hence, $(2.1)$ is $\left(h_{0}, h_{1}\right)$-practically stable.

Next we show that $(2.1)$ is $\left(h_{0}, h_{2}\right)$-practically stable. If $x\left(t, t_{0}, x_{0}\right)$ is some solution of (2.1) satisfying $h_{0}\left(t_{0}, x_{0}\right)<\lambda$. Then, by assumption $\left(A_{1}\right), A>\alpha_{2} \equiv \varphi_{2}\left(t_{0}, \lambda\right) \geq h_{2}\left(t_{0}, x_{0}\right)$. Choose $L(\lambda)$ such that $A>L(\lambda)>\max \left\{\lambda, \alpha_{2}\right\}$. Since $(2.1)$ is $\left(h_{0}, h_{1}\right)$-practically stable, and given $(\lambda, L(\lambda))>0$, we have that $h_{0}\left(t_{0}, x_{0}\right)<\lambda$ implies that $h_{1}(t, x(t))<L(\lambda), t \geq t_{0}$. We claim that $(2.1)$ is $\left(h_{0}, h_{2}\right)$-practically stable. If this is not the case, then there exist $t_{2}$ and $t_{1}$ such that $t_{2}>$ $t_{1}>t_{0}$

$$
\begin{gathered}
h_{2}\left(t_{1}, x\left(t_{1}\right)\right)=L(\lambda), h_{2}\left(t_{2}, x\left(t_{2}\right)\right)=A \text { and } \\
L(\lambda) \leq h_{2}(t, x(t)) \leq A \text { for } t \in\left[t_{1}, t_{2}\right], \text { whenever } h_{0}\left(t_{0}, x_{0}\right) \leq \lambda .
\end{gathered}
$$

Using the fact that $(2.4)$ is uniformly practically stable with respect to $\left(a_{2}(2 L(\lambda))+3 a_{0}\left(t_{0}, \lambda\right)\right.$, $\left.b_{2}(A)\right)>0$, we have that

$$
v_{0}<a_{2}(2 L(\lambda))+3 a_{0}\left(t_{0}, \lambda\right) \text { implies } v(t)<b_{2}(A), t \geq t_{0}
$$

for any $t_{0} \in \mathbb{R}_{+}$. As before, $V_{0}(t, x) \leq \frac{3}{2} a_{0}\left(t_{0}, \lambda\right)$ on $\left[t_{0}, t_{1}\right]$ and

$$
V_{2}\left(t_{1}, x\left(t_{1}\right)\right)+V_{0}\left(t_{1}, x\left(t_{1}\right)\right) \leq a_{2}(2 L(\lambda))+3 a_{0}\left(t_{0}, \lambda\right)
$$

by $\left(A_{5}\right)(c)$. Also, $D^{+}\left(V_{2}(t, x(t))+V_{0}(t, x(t))\right) \leq g_{2}\left(t, V_{2}(t, x(t))+V_{0}(t, x(t))\right)$. Consequently, by Theorem 2.1 ,

$$
V_{2}(t, x(t))+V_{0}(t, x(t)) \leq r_{2}\left(t, t_{1}, V_{2}\left(t_{1}, x\left(t_{1}\right)\right)+V_{0}\left(t_{1}, x\left(t_{1}\right)\right)\right)
$$


where $r_{2}\left(t, t_{1}, V_{2}\left(t_{1}, x\left(t_{1}\right)\right)+V_{0}\left(t_{1}, x\left(t_{1}\right)\right)\right)$ is the maximal solution of $(2.4)$ on $\left[t_{1}, t_{2}\right]$. Therefore by $(2.10),(2.11)$ and assumption $\left(A_{5}\right)(b)$,

$$
b_{2}(A) \leq V_{2}\left(t_{2}, x\left(t_{2}\right)\right)+V_{0}\left(t_{2}, x\left(t_{2}\right)\right)<b_{2}(A) .
$$

This results in a contradiction; therefore, $(2.1)$ is $\left(h_{0}, h_{2}\right)$-practically stable.

The next theorem gives conditions for which one can obtain uniform practical stability.

Theorem 3.2: Assume that the assumptions of Theorem 3.1 hold, except that $\left(A_{1}\right)$, $\left(A_{2}\right)(a)$ and $\left(A_{6}\right)$ are strengthened to

$\left.\left(A_{1}^{*}\right) \quad h_{1}(t, x(t)) \leq \varphi_{1}\left(h_{0}(t, x(t))\right), \quad h_{2}(t, x(t))\right) \leq \varphi_{2}\left(, h_{0}(t, x(t))\right)$, whenever $h_{0}(t, x(t))<\lambda$ and $\varphi_{1}(t, x(t)), \varphi_{2}(t, x(t)) \in K$;

$\left(A_{2}\right) \quad\left(a^{*}\right) \quad V_{0}(t, x) \leq a_{0}\left(h_{0}(t, x)\right)$ for $(t, x) \in S\left(h_{0}, \lambda\right)$, where $a_{0}(t, x) \in K$;

$\left(A_{6}^{*}\right) \quad a_{1}(A)+3 a_{0}(\lambda)<b_{1}(A), \quad a_{2}(2 A)+3 a_{0}(\lambda)<b_{2}(A), \quad \varphi_{1}(\lambda)<A$ and $\varphi_{2}(\lambda)<A$ hold for $t_{0} \in \mathbb{R}_{+}$.

If $(2.2),(2.3)$ and $(2.4)$ are uniformly practically stable, then $(2.1)$ is $\left(h_{0}, h_{1}\right)$ and $\left(h_{0}, h_{2}\right)$-uniformly practically stable.

Proof: The proof follows along the same lines as in Theorem 3.1 since the conclusions now holds for all $t_{0} \in \mathbb{R}$. results.

Under similar conditions, one can also obtain strongly uniformly practical stability

Theorem 3.3: Assume that the assumptions of Theorem 3.2 hold, with $\left(A_{5}\right)$ holding on $\mathbb{R}_{+} \times S\left(h_{2}, A\right) \cap S\left(h_{1}, L(\lambda)\right)$. Then, system $(2.1)$ is $\left(h_{0}, h_{1}\right)$-uniformly practically stable and $\left(h_{0}, h_{2}\right)$-strongly uniformly practically stable, provided $(2.2)$ and $(2.3)$ are uniformly practically stable and (2.4) is strongly uniformly practically stable.

Proof: By Theorem 3.1, $(2.1)$ is $\left(h_{0}, h_{1}\right)$-uniformly practically stable and $\left(h_{0}, h_{2}\right)$-uniformly practically stable. Therefore, it suffices to prove that $(2.1)$ is $\left(h_{0}, h_{2}\right)$-uniformly practically quasi-stable with respect to $(\lambda, A, B, T)>0$. Suppose (2.4) is uniformly practically-quasi stable with respect to $\left(3 a_{0}(\lambda)+a_{2}(2 A), b_{2}(A), b_{2}(B), T\right)>0$. Then,

$$
v_{0}<3 a_{0}(\lambda)+a_{2}(2 A) \text { implies that } v(t)<b_{2}(B), t \geq t_{0}+T,
$$

for any $t_{0} \in \mathbb{R}_{+}$, where $v\left(t, t_{0}, w_{0}\right)$ is any solution of (2.4). Suppose $x\left(t, t_{0}, x_{0}\right)$ is any solution of (2.1) satisfying $h_{0}\left(t_{0}, x_{0}\right)<\lambda_{0}$. Then $h_{2}(t, x)<A, t \geq t_{0}$ and $h_{1}(t, x)<L(\lambda), t \geq t_{0}$. Proceeding as in the proof of Theorem 3.1 , we obtain

$$
V_{0}(t, x(t))+V_{2}(t, x(t)) \leq r_{2}\left(t, t_{0}+T, V_{0}\left(t_{0}+T, x_{0}\right)+V_{2}\left(t_{0}+T, x_{0}\right)\right)<b_{2}(B),
$$

$t \geq t_{0}+T$. Consequently, $h_{2}(t, x)<B, t \geq t_{0}+T$, since

$$
b_{2}\left(h_{2}(t, x(t))\right) \leq V_{0}(t, x(t))+V_{2}(t, x(t))<b_{2}(B), t \geq t_{0}+T .
$$

Hence, $(2.1)$ is $\left(h_{0}, h_{1}\right)$-uniformly practically stable and $\left(h_{0}, h_{2}\right)$-strongly uniformly practically stable.

The following two theorems provide us with the assumptions needed to establish a combination of practical stability and stability.

Theorem 3.4: Let the assumptions of Theorem 3.1 hold with $\left(A_{5}\right)$ holding on $\mathbb{R}_{+} \times$ $S\left(h_{2}, A\right) \cap S\left(h_{1}, L(\lambda)\right)$. Then, $(2.1)$ is $\left(h_{0}, h_{1}\right)$-practically stable and $\left(h_{0}, h_{2}\right)$-asymptotically practically stable, provided (2.4) is uniformly asymptotically practically stable, (2.3) is uniformly 
practically stable and (2.2) is practically stable.

Proof: Let $\epsilon>0,(\epsilon<A)$. From Theorem $3.1,(2.1)$ is $\left(h_{0}, h_{1}\right)$-practically stable with respect to $(\lambda, L(\lambda))$ and $\left(h_{0}, h_{2}\right)$-practically stable with respect to $(\lambda, A)$. Therefore, it suffices to show that $\left(S_{1}\right)$ holds for $\alpha=\lambda$. Since (2.4) is uniformly practically asymptotically stable, given $\epsilon_{1}=b_{2}(\epsilon), t_{0} \in \mathbb{R}_{+}, \alpha_{1}=2 a_{0}\left(t_{0}, \lambda\right)+a_{2}(L(\lambda)+A)$, there exists a $T(\epsilon, \lambda)$ such that

$$
v_{0}<\alpha_{1} \text { implies that } v(t)<\epsilon_{1}=b_{2}(\epsilon), t \geq t_{0}+T \text {. }
$$

By assumptions $\left(A_{3}\right)$ and $\left(A_{5}\right)(a)$, we have that

$$
V_{0}\left(t_{0}, x\left(t_{0}\right)\right)+V_{2}\left(t_{0}, x\left(t_{0}\right)\right) \leq a_{2}(L(\lambda)+A)+2 a_{0}\left(t_{0}, \lambda\right) \equiv \alpha_{1} .
$$

We also have by $\left(A_{5}\right)$ that

$$
D^{+}\left(V_{0}(t, x(t))+V_{2}(t, x(t))\right) \leq g_{2}\left(t, V_{0}(t, x(t))+V_{2}(t, x(t))\right) .
$$

Consequently, by Theorem 2.1,

$$
V_{0}(t, x(t))+V_{2}(t, x(t)) \leq r_{2}\left(t, t_{0}, V_{0}\left(t_{0}, x\left(t_{0}\right)\right)+V_{2}\left(t_{0}, x\left(t_{0}\right)\right)<b_{2}(\epsilon) .\right.
$$

As a result, we obtain $h_{2}(t, x(t))<\epsilon$, since

$$
b_{2}\left(h_{2}(t, x(t))\right) \leq V_{2}(t, x(t)) \leq V_{0}(t, x(t))+V_{2}(t, x(t))<b_{2}(\epsilon),
$$

$t \geq t_{0}+T$. This completes the proof.

Theorem 3.5: Let the assumptions of Theorem 3.2 hold with $\left(A_{5}\right)$ holding on $\mathbb{R}_{+} \times$ $S\left(h_{2}, A\right) \cap S\left(h_{1}, L(\lambda)\right)$. Then, $(2.1)$ is $\left(h_{0}, h_{1}\right)$-uniformly practically stable and $\left(h_{0}, h_{2}\right)$-uniformly asymptotically practically stable provided (2.2) is uniformly practically stable, (2.4) is uniformly asymptotically practically stable and (2.3) is uniformly practically stable.

Proof: The proof the the uniform practical stability follows along the same lines as in Theorem 3.1; whereas, the proof for the uniformly attractive in the large is the same as that in Theorem 3.3.

As a special case of the above theorem, we have the following corollaries which do not require the knowledge of the comparison equations.

\subsection{Corollaries}

Corollary 3.1: Assume that assumptions $\left(A_{1}\right)$ through $\left(A_{6}\right)$ of Theorem 3.1 hold with assumptions $\left(A_{3}\right)(b),\left(A_{4}\right)(c)$ and $\left(A_{5}\right)(c)$ replaced by

$\left(A_{3}\right) \quad\left(b^{*}\right) \quad D^{+} V_{0}(t, x(t)) \leq 0$ on $\mathbb{R}_{+} \times \mathbb{R}^{n} ;$

$\left(A_{4}\right) \quad\left(c^{*}\right) \quad D^{+}\left(V_{0}(t, x(t))+V_{1}(t, x(t))\right) \leq 0$ on $S^{c}\left(h_{1}, \lambda\right) \cap S\left(h_{1}, A\right)$;

$\left(A_{5}\right) \quad\left(c^{*}\right) \quad D^{+}\left(V_{0}(t, x(t))+V_{2}(t, x(t))\right) \leq 0$ on $S\left(h_{2}, A\right) \cap S\left(h_{1}, L(\lambda)\right) \cap S^{c}\left(h_{2}, L(\lambda)\right)$.

Then, (2.1) is $\left(h_{0}, h_{1}\right)$ and $\left(h_{0}, h_{2}\right)$-practically stable.

Corollary 3.2: Assume that the assumptions $\left(A_{1}\right)$ through $\left(A_{6}\right)$ of Theorem 3.2 hold with assumptions $\left(A_{3}\right)(b),\left(A_{4}\right)(c)$ and $\left(A_{5}\right)(c)$ replaced by assumptions $\left(A_{3}\right)\left(b^{*}\right),\left(A_{4}\right)\left(c^{*}\right)$ and $\left(A_{5}\right)\left(c^{*}\right)$ in Corollary 3.1. Then, $(2.1)$ is $\left(h_{0}, h_{1}\right)$ and $\left(h_{0}, h_{2}\right)$-practically stable.

Corollary 3.3: Assume that assumptions $\left(A_{1}\right)$ through $\left(A_{6}\right)$ of Theorem 3.4 hold with assumption $\left(A_{5}\right)(c)$ replaced by 
$\left(A_{5}^{*}\right) \quad\left(c^{*}\right) \quad D^{+}\left(V_{0}(t, x(t))+V_{2}(t, x(t))\right) \leq-C\left(h_{2}(t, x(t))\right)$ on $S\left(h_{2}, A\right) \cap S\left(h_{1}, L(\lambda)\right)$. Then, $(2.1)$ is $\left(h_{0}, h_{1}\right)$-practically stable and $\left(h_{0}, h_{2}\right)$-asymptotically practically stable.

The proofs of the above corollaries can be obtained by appropriate modifications of the proofs in our main results.

\section{References}

[1] Köksal, S., Boundedness properties and perturbing Lyapunov functions, J. Math. Anal. Appl. 163 (1992), 73-78.

[2] Lakshmikantham, V., Leela, S. and Martynyuk, A.A., Practical Stability of Nonlinear Systems, World Scientific, Singapore 1990.

[3] Lakshmikantham, V., Leela, S. and Martynyuk, A.A., Stability Analysis of Nonlinear Systems, Marcel Dekker, New York 1989.

[4] Lakshmikantham, V. and Leela, S., On perturbing Lyapunov functions, Math. Systems Theory 10 (1976), 85-90.

[5] Lakshmikantham, V. and Liu, X.Z., Stability Analysis in Terms of Two Measures, World Scientific, Singapore 1993.

[6] La Salle, J. and Lefschetz, S., Stability by Lyapunov's Direct Method and Applications, Academic Press, New York 1961.

[7] Stutson, D. and Vatsala, A.S., Composite boundedness and stability results by perturbing Lyapunov functions, Nonlinear Analysis (1995), to appear. 


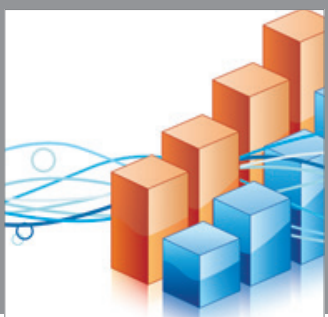

Advances in

Operations Research

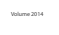

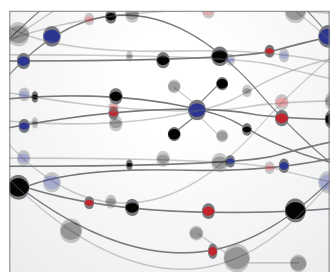

\section{The Scientific} World Journal
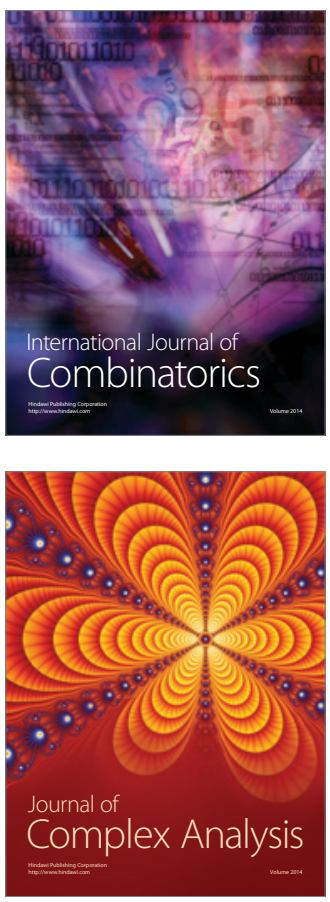

International Journal of

Mathematics and

Mathematical

Sciences
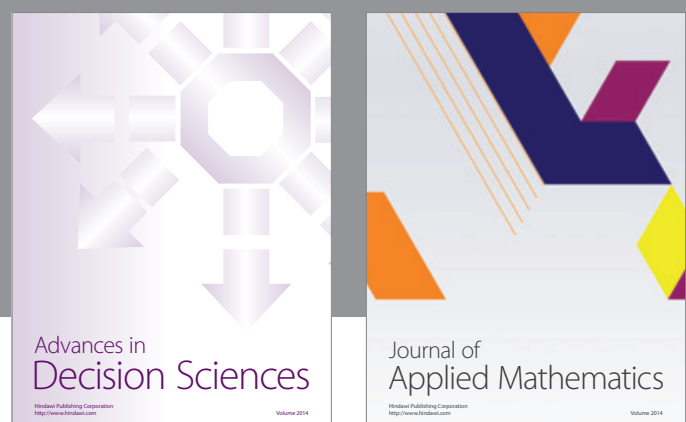

Journal of

Applied Mathematics
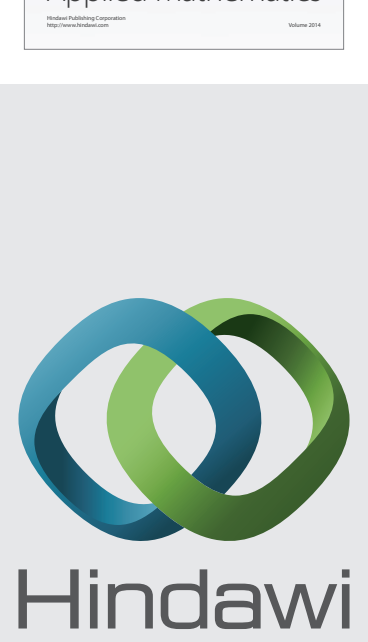

Submit your manuscripts at http://www.hindawi.com
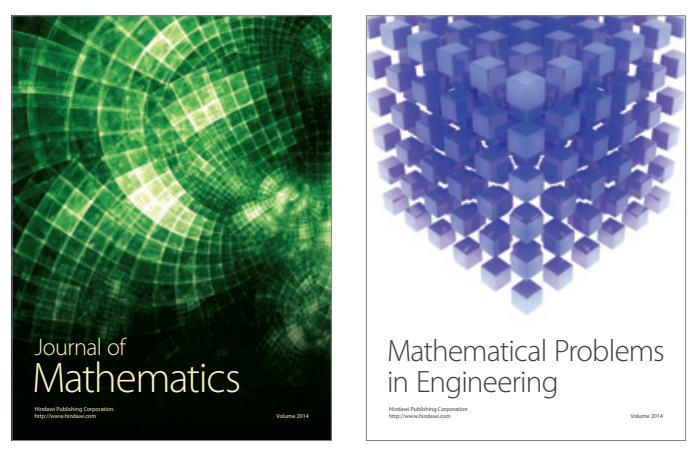

Mathematical Problems in Engineering
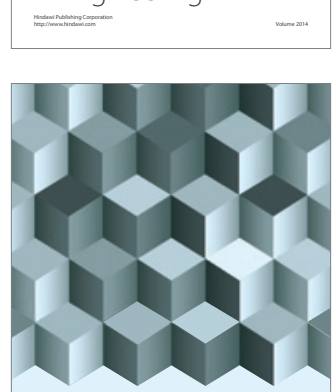

Journal of

Function Spaces
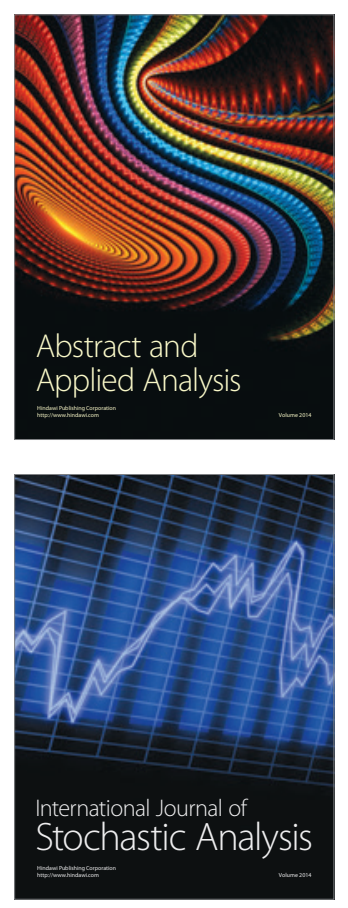

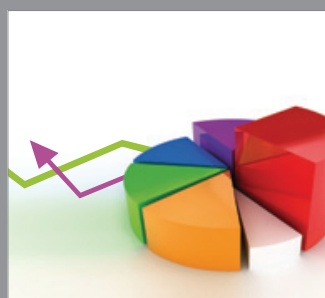

ournal of

Probability and Statistics

Promensencen
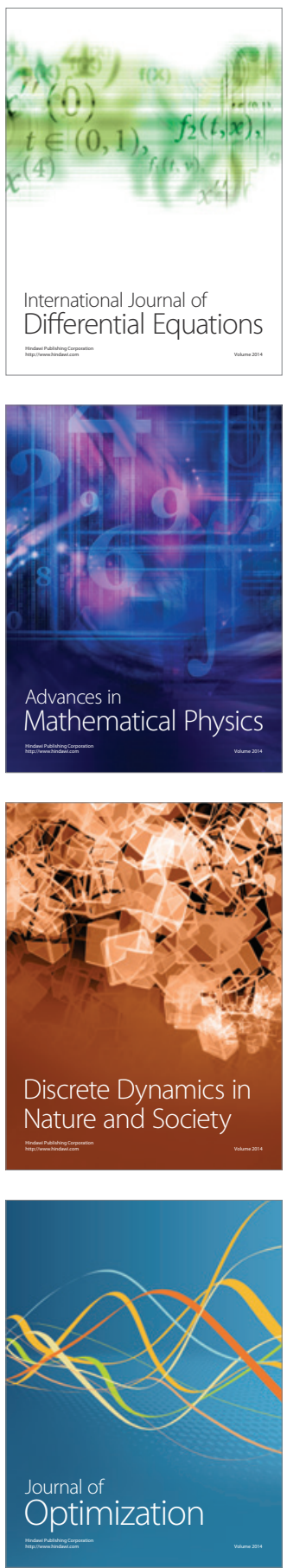